\title{
The Gap between Mind and World in Mind and World Remains
}

\author{
Chung-I. Lin ${ }^{1,2}$ \\ ${ }^{1}$ Graduate Institute of Humanities in Medicine, Taipei Medical University, Taipei, Taiwan \\ ${ }^{2}$ Department of Philosophy, National Chengchi University, Taipei, Taiwan \\ Email: cyberlin@nccu.edu.tw
}

Received March $1^{\text {st }}$, 2013; revised April $3^{\text {rd }}$, 2013; accepted April 17 ${ }^{\text {th }}, 2013$

\begin{abstract}
Copyright $@ 2013$ Chung-I. Lin. This is an open access article distributed under the Creative Commons Attribution License, which permits unrestricted use, distribution, and reproduction in any medium, provided the original work is properly cited.
\end{abstract}

\begin{abstract}
In Mind and World, McDowell endorses: empirical thoughts should be justified, ultimately, by things they are about; and, that empirical thoughts are immediately about their ultimate justifiers. But, it also holds two other views: first, as we relate our empirical judgments to their credentials, we ultimately rely on experience, despite its fallibility; second, our empirical judgments are about things in the external world. These views appear inconsistent with one another. McDowell's way of accommodating the seeming inconsistency appeals to the idea of conceptuality of experience and the holism of the conceptual. Mainly by an argument from false experience, I demonstrate that the conceptual resources relevant to McDowell's idea of the conceptuality of experience fall short of delivering the accommodation he promises.
\end{abstract}

Keywords: McDowell; Objectivity; Conceptuality of Experience; False Experience

\section{Introduction}

There are two closely related core convictions of McDowell's Mind and World: One is that empirical thoughts should be justified, ultimately, by things they are about; the other is that empirical thoughts are immediately about their ultimate justifiers. Denying the above relations between the notion of justification and that of intentionality will render both unintelligible. As intentionality gone, the world will be closed from our mind. But, these convictions seem to be incoherent with the following theme of Mind and World.

According to McDowell, a germane conception of experience should accommodate the following two commonsensical views. The first is an empiricistic conviction that as we relate our empirical judgments to their credentials, we ultimately rely on experience, despite its fallibility. (cf. McDowell, 1994: pp. 4-6. A clear statement of the idea and its origin can be found in his 1998b: pp. 435-436.) Let's call this the justification feature of experience. The second point regards intentionality and objectivity: our empirical judgments are about things in the external world, a world that ranges beyond our thoughts and experiences. Let's dub it the intentionality feature of empirical thinking. It appears that these commonsensical views together betray the conviction aforementioned: the former has it that empirical thoughts are about non-experiential things, but the latter has it that empirical thoughts are nonetheless justified by experiences.

In Mind and World and elsewhere, McDowell promotes a way of seeing experience, which he argues would suffice to accommodate and make coherent the two commonsensical views. In McDowell's words, this way of seeing experience "enables us to acknowledge that independent reality exerts a rational control over our thinking," (1994: p. 27) and "secures that we can see observational judgments as rationally responsive to the states of affairs they judge to obtain.” (2000: p. 15) Surprisingly, the key of the accommodation hangs on the idea of conceptuality of experience: whatever manifests in and through experience is constitutively-though passively-involved with conceptual capacities, which are to be identified with the faculty of concepts exercising in the self-critical activity of making up one's own mind. In fact, it is the holism of the conceptual that makes intelligible the idea that what experience manifests exerts objective constraints over our empirical thoughts.

In this paper, I shall first introduce McDowell's characterization of the conceptuality of experience. Then, I argue that the conceptual resources relevant to McDowell's idea of the conceptuality of experience fall short of delivering the accommodation he promises. My main argument appeals to the notion of false experience. I argue that McDowell's claim of the conceptuality of experience would, however, apply to all experiences generally, including false experiences, notably illusions and hallucinations. That is, McDowell is committed to a position that implies that false experiences also impose rational and external constraints over our empirical beliefs. This in turn implies that, for McDowell, the content of a false experience is objective, which would be absurd. This approach either renders the notion of false experience unintelligible or sells short the notion of objectivity, and hence intentionality.

A word of clarification about the nature of McDowell's accommodation of objectivity and intentionality might be helpful. Even though McDowell's philosophy is mainly diagnostically oriented, the rationale for the accommodation, as the phrase "enables us to acknowledge" indicates, is clearly rendered in a constructive spirit. With this understanding, I expect that the dispute constructed in this paper should not be dissolved by 
way of a metaphilosophical campaign.

\section{The Conceptuality of Experience}

McDowell's idea of the conceptuality of experience is rich and complex, but his characterization of it is concise and, occasionally, tends to be elusive. To address our concerns, however, we can pin down two characteristic elements of his picture of experience. Let's call them the identity claim and the passivity claim.

\section{The Identity Claim}

For McDowell, experience is conceptual through and through, and the conceptual capacities involved in experiences "are capacities whose paradigmatic actualizations are exercise of them in judgment, which is the end - both aim and culmination-of the controlled and self-critical activity of making up one's mind." In fact, McDowell writes, "we identify the relevant range of capacities by considering their role in" active selfcritical thinking (1998a: p. 410). In this view, whatever conceptual capacities are actualized in the receptiveness of sensation can be exercised in the activity of self-critical thinking, though it does not claim that whatever concepts are found through active thinking can be found in experience.

We can make the point of identity more explicit and ward off possible misconception by considering empirical judgments that are said to be based directly on experience. According to McDowell, an empirical judgment can be made through active thinking by simply selecting part of the content of an experience and non-inferentially endorsing that content. Such a judgment is an empirical judgment based directly on experience. The judgment shares at least part of the content of the experience on which it is based. "[The] grounding need not depend on an inferential step from one content to another. The judgments that things are thus and so can be grounded on a perceptual appearance that things are thus and so.” (1994: p. 49, n. 6, also his 2006: p. 1068.) It has to be noticed that when a judgment is based directly on an experience, the judgment "does not introduce a new kind of content, but simply endorses the conceptual content, or some of it, that is already possessed by the experience on which it is grounded” (1994, pp. 48-49). The point of caution I would like to make here is that when McDowell says that we look for the identification of the conceptual capacities in experiences with those that are exercised in active thinking, he does not thereby commit to the notion that active thinking, when connected to an experience, changes the content of the experience or brings conceptual content into it to make it conceptual. When we connect judgments to an experience, all we have done is endorse, reject, or doubt (or some other kind of critical assessing) the conceptual content already contained in the experience.

\section{The Passivity Claim}

The major difference between the conceptuality of experience and thinking activity is the modes they actualize: conceptual capacities are actively exercised in thinking; in experience, they operate or are involved passively. The passivity he refers to is first characterized in terms of involuntarity. It is not, typically, under a subject's control to decide what is to be experienced; but, in paradigmatic thinking, it is up to the subject itself to decide what to think. This characterization requires some elaboration. First, since there are involuntary thoughts, the conceptual actualizations that are experiences must be an involuntariness of a specific kind. To clarify this, we might find a clue in the following remark: "in a visual experience an ostensibly seen object ostensibly impresses itself visually on the subject. Presumably parallel things are to be said about other sensory modalities” (McDowell, 1998b: p. 441). In experiences, the contents of the experience are "imposed" or "impressed" on the subject (or, "required" or "necessitated" from) by the objects ostensibly sensed. (cf. 1998b: pp. 440, 451) The notion of passivity of experience thus contains the notion of ostensible imposition or impression. The way we understand this notion of "ostensible imposition" forms a basis for much of the dispute I raise in this paper, but I shall come to it later. Second, in the case of paradigmatic judgment, we endorse the contents of such active thinking, but, as I have pointed out previously, it is not necessarily so in the case of experience. The notion of passivity of experience implies the possibility of non-endorsement. Or, more generally put, experience by itself, although it may be conceptual through and through, is yet to be evaluated by active thinking.

\section{The Ultimate Empirical Justification and the Passivity of Experience}

Can the identity claim and/or the passivity claim enable us to acknowledge the justification feature of experience and the intentionality feature of empirical thinking? I propose that they cannot. Let's first consider the justification feature of experience. What we mean by the justificatory feature of experience consists of two ideas: first, an experience can be taken as a reason for endorsing some empirical judgment; second, experience is what we usually appeal to in the course of justifying our empirical thoughts. It should be clear that we need the claim of identity to be able to accommodate the first idea. If we wish an experience to serve in a justificatory role for empirical thinking, it must be conceived as a reason. A reason is, for McDowell, propositionally contentful, hence its constitution must involve conceptual resources. But for experience to be a justifier of empirical thinking, the conceptual capacities involved in the former must be identical with those involved in the constitution of the latter. Say, the experience that there is a red table is jointly involved with, at least, two capacities, one of which also partakes in the judgment that there is a red chair and the other in the judgment that there is a black table. If the identity relation does not hold, neither of the two judgments could acquire the rational link required for their justifications to rest on experience. The rational link would not obtain even if we downgrade just a bit the content of the experience to something less than fully conceptual, say "protoconceptual" or "semi-conceptual.” The general point of this example obviously chimes with Sellars' observation that in order of justification, our empirical judgments are, as traditional empiricism contends, resting on sensory reports, but at the constitutional level, and hence the level of understanding, sensory reports are, contrary to traditional empiricism, resting on judgments. (cf. 1965: §38, 300; $\S 19,275)$.

I have no quarrel with the above idea, and I am willing to accept the further proposition that when experience is conceived as constitutively involved with conceptual elements which could be found in some active thinking, it suffices to 
play a role in the justification of empirical thoughts. But to fully accommodate the justificatory feature of experience, McDowell has to say something more. To repeat, in McDowell's conception, experience not only plays a role in the justification of empirical judgments, which is a role that empirical thoughts can play too, but also a prior or even privileged role in the justification; it is what we appeal to in the final step of justifying our empirical thoughts. To respect the priority, experience must directly manifest facts in the world. In McDowell's words, "we can make sense of the idea ... that the ultimate credentials for theory [worldview] lie in experience ... only because we can make sense of experience as bringing objects into view" (1998b: pp. 464-465).

It is noteworthy that the idea of "bringing objects into view" has some very interesting and important ramifications about the nature of the world. To mention only the most important and somehow peculiar one: It is that not only experience, but also the world now that would have to be conceived as conceptual through and through. This point can be seen from a different angle. If the world is not conceptual, it cannot exert rational constraints over our empirical thinking. A non-conceptual item cannot be a reason, and therefore cannot pose any rational constraints over anything.

I am also willing to grant the idea that unless experience manifests facts, it cannot be the ultimate ground for justifying empirical thoughts. But the question that concerns us is whether experience can indeed manifest things as they are in the objective and external world. And the answer depends on how we understand the metaphor of "bringing objects into view".

Since both experience and active thought are sufficient justifiers, it seems more productive to reorient our discussion for a moment from the identity claim to the passivity claim to see whether it helps us to make sense of the idea of "bringing objects into view". In this vein, the "in-view" idea is supposed to be cashed out by the idea that the contents of experiences are "imposed" or "impressed" on their subjects by the objects ostensibly sensed. (1998b: p. 440) But, the term "imposition" or "impression" itself is vague. Is the imposition a relation belonging to the realm of law or logic? McDowell certainly would not agree that it is the former; the realm of law, for McDowell, is below the line of the rational and hence things in the realm that cannot function as reason. McDowell distinguishes two mutually exclusive ways of making sense of nature: one is seeing it as "the space of reason"; the other, as "the realm of laws". The space of reasons is the "space for the categories whereby we express our spontaneity-categories of meaning, intentionality and normality," and, on the other hand, the realm of law is "the realm of what is intelligible in terms of the kind of laws which natural science aims to discover.” (1994: pp. 5-13 and 70-86).

But, it can neither be a logical relation, for the following reason. If it were a logical relation, it should be that if such and so is the case, when faced with the case, we will sense that it is such and so. This is not acceptable, since it leaves no room for the idea of non-veridical experience. In any case, this is not what McDowell has in mind in regards to the notion of imposition. Consider what McDowell says in the following remark. (1995: pp. 887-888, n. 18).

When it turns out that the world has played us false, we conclude that it has presented us with a mere appearance rather than a manifest fact. Moreover, when the world does present us with a manifest fact, it does so by presenting us with an appearance... Of course the content of the appearances that the world presents us with ("appearances" is here neutral as between "mere appearance" and "manifest fact") is not irrelevant to our possession of factive standings in the space of reasons. Our being able to count as, say, seeing that things are thus and so depends on our being properly sensitive (where "properly" expresses a rational assessment) to how things look to us.

If the world can misguide us, inducing misrepresentations in our senses, then the relation between the world and the content of an experience it induces cannot be logical.

The nature of the relation between the content of an experience and the relevant fact in the external world is not clearly in view yet, but, as in the last sentence just cited, when McDowell credits an experience with "bringing facts in view", he often, though not always, adds a condition to the experience. It is that the experience must be true or the world is "properly" sensed by it. This, by itself, makes perfect sense. But one can suspect that the qualification indicates that McDowell is in fact unloading burden of explaining the notion "bringing facts in view" onto the notion of truth. However, if it is truth that plays the central role in the matter, McDowell would render the matter trivial and shift the matter in a direction which he himself does not favor. Let me explain. It is not controversial to say that when an experience is true, it manifests some fact. In fact, it is not even controversial to say that when an empirical thought is true, it "manifests" some fact in the world. It is so not only because of the vagueness of the term "manifest", but more importantly, because of the following parallel. For McDowell, when an experience is said to be manifesting some fact, it shares with the fact in question the same content, and vice versa, given the condition that the subject is faced with the fact. Now, if an empirical thought shares with the relevant fact the same content, it seems that we will have no reason to deny the thought the status of manifesting the fact. The priority role of experience in empirical justification would then be gone, as its function of "manifesting" facts is no longer in some way privileged.

As it turns out, if it is the notion of truth that plays the central role in explaining how facts come in to view, philosophers like Davidson taking the opposite position would have quite a solid foothold, which might be gained by simply appealing to the dubious nature of experience attacked on both semantic and epistemological fronts, to support a certain kind of belief whose occurrences are directly conditioned by the immediate environment. The reason why McDowell needs to assert the conceptuality of experience to explain the ultimate justification feature of experience would then become obscure.

In the last paragraph we assert that if we allow there is a kind of belief that is delimited by the occurrences which are directly conditioned by the immediate environment, it becomes unclear why we need "experience" in between "mind" and "world" for an understanding of intentionality and empirical knowledge, as McDowell asserts. The point here can be put differently in terms of the notion of passivity. Passivity is one of the hallmarks of McDowell's characterization of experience, which is necessary in order to say experience and therefore empirical thinking in general can be open to the world. But I cannot see any decisive reason why the notion of passivity is improper in sorting out a class of beliefs or thoughts. It is perfectly com- 
monsensical to say that when some fact such and so is directly presented to me, I usually cannot help but believe such and so; and this "cannot help" usually does not happen in those cases where things I believe do not occur nearby. It seems that all that McDowell wants experience to do, the purpose he wants it to serve, can be done by this kind of belief. If so, we do not need "experience" to understand intentionality and knowledge.

One might suggest that an answer can be found in McDowell's statement that "our being able to count as, say, seeing that things are thus and so depends on our being properly sensitive (where 'properly' expresses a rational assessment) to how things look to us” (1995: pp. 887-888, n. 18). The appeal to rational assessment, however, does not help us out of the situation. First, the remark indicates clearly only that one can say that he sees that $\mathrm{P}$ only if he rationally assesses his experience with the content $\mathrm{P}$, but it is not clear that the opposite direction of the conditional likewise holds, which is what we really need to resolve the issue. Second, even if the remark does suggest the opposite of what is implied, it would more likely undermine rather than explain the privileged role of experience in empirical justification. If experience, or how things appearance to us, is not sufficient to assure us of its "openness to facts" and, we need, additionally, some rational assessment of experience, then experience, by itself, cannot have the final say on how things are. Perhaps, it is not only experience alone, but the cooperation of experience and our capacity for rational assessment that enable us to acknowledge the ultimate role of empirical justification. One can hold the view that when an experience passes rational assessment, it itself alone can be said to be open to the world. But this suggestion will not do. Consider two cases. First, suppose that it is a fact that $\mathrm{P}$, and $\mathrm{P}$ induces two phenomenologically indistinguishable experiences, but one is veridical and the other false. Since the contents of the two experiences are identical phenomenologically, the basis for the empirical justification, for the subject in question, cannot be granted to experience, but only to our rational assessment of it. On the other hand, suppose that $\mathrm{P}$ induces two phenomenologically distinguishable experiences, then there are two ways of making sense of the difference: one is through rational assessment of the propriety of the connections among the contents of the senses and other conceptual occurrences; the other is by way of investigating the causal relations between $\mathrm{P}$ and the two senses. In the first case, we are either spinning in a void of a coherentistic justification, or we presuppose, but cannot explain, the idea that our world view is in general true; in the other case, we are playing a sideways-on game McDowell would not allow; one characteristic of McDowell's thinking is that the realm of the conceptual is unbounded, so there is no standpoint outside the conceptual for rational assessment or causal (which is non-rational for McDowell) investigation into the relation between a conceptual occurrence and things in the world. ( $c f$, for example, his 1994: 35f, 81).

For McDowell, being in the space of reason, that is being rational, intentional and cognitive, requires having the world in view, i.e., having the truth in grasp ( $c f$, for example, his 1995: pp. 880-883). In this view, "mere appearance” should be understood on the basis and in terms of "manifesting fact". This is the core of McDowell's pre-emptive strategy for dissolving radical skepticism. I have no dispute with the requirement of having the world in view for being intentional. But McDowell offers no conclusive argument for us to believe that the requirement can be fulfilled.

\section{The Conceptual, the Objective and the External Constraint}

The line we have traced so far is mainly epistemological, but it points to a way of understanding how McDowell accommodates the intentionality feature of empirical thinking. For McDowell, to say that our empirical thinking traces its justificatory route ultimately to experiences is to say that our empirical thoughts are ultimately responsive to what experiences manifest. Empirical judgments seek ultimate justifications from what they are about. But, of course, for McDowell, empirical judgments are not about experiences; they are about the external world. So there is a further step to take. It is that we are required to conceive experience as something that could directly manifest the external world, a world independent of our thinking. In McDowell's words, “concepts, which make thought what it is, can intelligibly be what they are-thought can intelligibly be of the objective at all—only because we can see how there can be conceptual occurrences in which objects are manifestly there for thinkers, immediately present to their conceptually shaped sensory consciousness” (1998b: p. 465).

But what is the rationale for the claim that conceptually constituted experience can directly manifest the objective? This is the question we continue asking and left unanswered in the last section. A possible answer emerges when we transform our question into the question of how does the conceptuality of experience make intelligible the idea that the world manifested through experience does exert "external" constraints on our empirical thinking? The "external” constraints cannot be some constraints imposed from outside the conceptual, since it would then become a non-rational constraint. For McDowell, an external constraint is a constraint coming from outside thinking activity and experience.

One might suggest that the notion of "external" constraint or objectivity hangs on the notion of passivity. But, as I have pointed out, the way McDowell characterizes the passivity of experience should exclude this possibility. To repeat, McDowell characterizes the particularity of the involuntariness of, say, visual experience in terms of "in a visual experience an ostensibly seen object ostensibly impresses itself visually on the subject” (1998b: p. 441) But, however germane the characterization is, it cannot non-circularly explain the "externalness" of the constraint imposed from experience. To use the statement "in a visual experience an ostensibly seen object ostensibly impresses itself visually on the subject" to characterize the involuntariness of a visual experience is simply to assume, as the word "ostensibly" suggests, that the visual experience is about something "external" to the experience.

It would be hasty to conclude here that room for an effective explanation of objectivity cannot be found in the realm of involuntariness. But, here it is reasonable and may be more productive to reorient from the dimension of passivity back to the conceptual dimension of cognitive phenomena. And this is the path McDowell clearly has set on. He says, "there can intelligibly be such conceptual occurrences [experience manifesting objective objects] only because we can see how thought can also be related to its subject matter in a way that is mediated by theory [world-view]" (1998b: p. 465).

The identity claim asserts that the conceptual capacities saddled in experience and exercised in active thinking are identical. Thus, the content of an experience could also be the content of an active thinking: what is experienced could be considered and 
reconsidered by thinking. In addition to the identity thesis, McDowell proposes a view that can be named the integration thesis. According to McDowell, the conceptual capacities involved in active thinking, or an experience, cannot be conceived atomistically. The conceptual capacities do not function in isolation; they are seamlessly interconnected with one another. More specifically, conceptual capacities actualized in a given judgment are part of the whole package of conceptual capacities of a thinking self, but the whole range of conceptual capacities are rationally connected with one another. "They are integrated into a rationally organized network of capacities” for active self-critical thinking (1994: p. 29). By linking into the network, the active self-critical thinker holds a particular judgment in place, such that the judgment can be supported, modified, or overturned in light of its various rational connections with other judgments.

Now, since whatever conceptual capacities embedded in a given experience are also to be found in some self-critical activity, and since the very same conceptual capacities are seamlessly integrated into a larger network of conceptual capacities of self-critical activity, the conceptual capacities exercised in the self-critical activity go beyond those that embedded in the experience. Thus, the content of an experience can be considered and reconsidered by the critical subject by way of its rational connections to other conceptual activities. Thereby, the objectivity conclusion is arrived at: "It is this integration that makes it possible for us to conceive experience as awareness, or at least seeming awareness, of a reality independent of experience” (1994: p. 31). By virtue of this part-whole integration of the conceptual capacities passively actualized in experience and actively excised in thinking, the subject understands that what an experience manifests is part of a thinkable world, a world that ranges beyond what the experience tells.

The part-whole integration makes space for this understanding of the objectivity of a thinkable world for a simple reason: the thinkable whole is independent of what any given experience can manifest. McDowell uses the word "independent" in a particular manner here. It is not that the thinkable whole can exist in the absence of the content of an experience, but that the conceptual content actualized in the experience can be held in place as a part by means of a conceptual storage, and thus be considered and reconsidered even "if the experience had not occurred" (1994: p. 36, my emphasis). In this precise sense, McDowell says that what an experience is about can be conceived as part of a world independent of the experience itself.

However, the idea that the thinkable world is independent of any given experience is not sufficient to assure us that the thinkable world is independent of subjective activity in general, for it is yet to be determined that the thinkable world is independent of thinking activity. It seems that McDowell needs more than this for the assurance of objectivity. This, however, would not be a serious problem for McDowell, since we can construct a supplemented argument for the needed thesis in a similar fashion to that McDowell has used for the objectivity of experiential content. It goes as follows.

Any thought can be thought of. We might say that any thought is subject to second order thinking, thinking about thought. And it should be admitted that any thinking activity is an actualization of some conceptual capacity. Now the identity thesis and the integration thesis that apply to experience should both be applicable to thought and higher order thinking. The conceptual capacities involved in a thinking activity and those exercised in some higher order thinking are identical. And those capacities are integrated into a wider network of conceptual capacities of self-critical thinking. That allows us to say that the content of any given thought can be reconsidered in higherorder thinking by connecting it to wider ranging conceptual capacities than those originally connected to the thought. We may first form a judgment, then rethink, doubt, and refine it, in the course of a continuous thinking activity. Since a particular thought has to occur at a given time, and we can think of the thought at a later time, the content of a thought can be entertained while the original thought no longer occurs. We might thus arrive at the understanding that the content of a thought is independent of the thought itself. In general, we can say that thinkable content is something that is independent of, or external to, thinking activity.

With this argument, McDowell's argument for the objectivity of the content of experience is complete. McDowell reminds us that since what is experienced can be entertained in thought, what is experienced is independent of any experience. Now, since the content of any given thought can be reconsidered in a different manner while the original thought no longer exists, what the thought is about is independent of the thought itself, which is a thinking activity. We may say that even though every thought has to be thought of, what is thought of is independent of thinking activity. Thus, we reach the conclusion that what is experienced is independent of, or external to, thinking activity in general.

So it seems that the identity claim has the best shot at making the intentional feature of our empirical thinking intelligible. But I should argue that the identity claim, even when supplemented with the integration thesis, is still less than sufficient to assure us of the intentional feature of our empirical thoughts.

\section{False Experience, the External and the Objective}

It should be clear by now that whatever kind of episode or state to which self-criticism is applicable, its objective status, that McDowell intended to assure us of, is of the kind that could be established by means of the thesis of identity and the thesis of integration. Arguments can be easily constructed for McDowell to show that norms, worldviews, values and whatever governs or directs our ways of thinking and acting are subject to self-criticism ( $c f, 1994$ : pp. 1-2 and 81), and so they are objective in the relevant sense. It would be fair to say that for McDowell, all of these things exert rational and "objective" constraints over our thinking. But it is very dubious to say that norms, values and worldviews exert "external" constraints over our empirical judgments. The reasons, simply put, are these. First, if everything that is thinkable exerts rational and external constraint over our thinking, then the privileged role of experience in empirical justification is gone or, at least, yet to be vindicated. Moreover, false thoughts (including the judgment that my twin sister, who never existed in fact, is $300 \mathrm{~cm}$ tall) are subject to critical thinking, but we do not want at all to say that the content they contain reflects external constraints over our thinking, like those exerted by experiences. So, the notion of "the external" must be different from the notion of "the objective”.

Perhaps, one might hope that if we permit McDowell the notion of "ostensive imposition", McDowell might be rescued from our previous criticism. But this will not do either. It must 
be noted that the theses of identity and integration also apply to illusion and hallucination [hereafter, the term "false experience" refers to both illusion and hallucination, unless a necessity is called for]. False experience is subject to critical thinking and therefore is conceptual. Moreover, for critical thinking about false experience to be possible, the conceptual capacities involved in a false experience and those exercised in critical thinking about it should be identical. And those capacities are integrated into a wider network of conceptual capacities of self-critical thinking. That is, the identity thesis and the integration thesis that apply to veridical experience should also be applicable to false experience. That allows us to argue that the content of any given false experience can be reconsidered through active thinking by connecting it to wider ranging conceptual capacities than those involved in the experience itself. We may first have a false experience, then think, doubt, and refute it through a continuous thinking activity. Since a particular false experience occurs at a given time and we can think of the thought at a later time, the content of the experience can be entertained while it no longer occurs. We might thus arrive at the understanding that the content of a false experience is independent of the experience itself. In general, we can say that content of a false experience is something that is independent of any experience. And with the argument found in the previous section, we can say that what false experiences represent is mind-independent in the relevant sense.

Moreover, McDowell would agree that the content of a false experience, like that of a veridical one, is ostensibly imposed on a subject by objects ostensibly sensed. Now, if this shows that the false experience manifests something "external” to the experience and to the mind of the subject, then we can say that, for McDowell, what has manifested in and through a false experience has rational, objective and external constraint over our empirical thoughts. In terms of intentionality, the result would be that some of our empirical thoughts are based on false experiences. This would certainly not be acceptable. The project of Mind and World mainly concerns the objective purport of empirical thinking and experience in general, and when McDowell says that the world manifested through experience has rational and external constraints over out empirical thinking, he does not limit experience to veridical experience. When we are talking about the objective purport of empirical thinking and experience, we are saying that they are about something real, not fictional, of course. Experiences, veridical or not, are about the objects in the same world, or there would be of no sense in talking about false experience.

McDowell secures the sense of objectivity and intentionality by way of showing that experience, as he sees it, manifests something that exercises rational and external constraints over our empirical beliefs. However, I have pointed out that this assurance not only applies to veridical experiences but also false experiences. That is, McDowell appears to be committed to the position that false experiences, just like veridical ones, manifest rational and external constraints over our empirical beliefs. This entails the dubious idea that what a false experience manifests is objective. But, non-veridical experiences clearly do not manifest facts, and some of them, e.g., hallucinations, are even about things that do not exist in reality. Therefore, if what false experiences manifest are objective and external things just as veridical experiences do, then at least some of things manifested through false experiences are located in "worlds" different from the world, the real one, that veridical experiences manifest. But, there is no clear sense to the idea that false experiences manifest things in some world different from the real one. Was the experience "the face of the boy is triangle" about a boy with a triangular face existed in a fancied world, it will not be an illusion. Was John's experience "my sister is a pretty lady" (a sister never exist in the real world) is about a sister of his in a fancied world, it will not be a hallucination. Thus, experiences, veridical or not, must be about things in the same objective and external world, or there is no sense of the idea of a false experience.

One might ask why my explication has skipped over the disjunctivistic conception of experiential content that one might find in McDowell's thought. The reason is simply that it does not matter. Even though my argument appeals to the notion of false experience, it does not assume or entail the idea that false experiences and veridical ones share some common factor in their contents or that they have equal epistemic status. My argument from false experience is meant to show that McDowell's argument for the objectivity of experience applies generally to both veridical and non-veridical experiences. The application has the dubious result that that non-veridical experiences have content that is objective in the very same sense that the contents of veridical experiences are. My argument has nothing to do with whether a veridical experience shares some of its content with its corresponding false experience.

\section{Concluding Remark}

McDowell asserts the conceptuality of experience in order to assure us of the intentionality and objectivity of experiences. But this assurance is invalid. The conceptual resources relevant to McDowell's idea of the conceptuality of experience do not suffice for the task. The main point of this paper is to show that as long as the content of a false experience is conceptual, then, for McDowell, it must be objective and imposes external and rational constraint on some of our empirical thoughts. Since experience must eventually answer to what it is about, the content of an experience must thus be what the experience is about. As I have shown, this would render the idea of false experience, such as illusion or hallucination, unintelligible. The result clearly shows that McDowell needs more than the assertion of the conceptuality of experience to accommodate not only the intentionality feature of our empirical thoughts but also the justification feature of our experience.

\section{REFERENCES}

McDowell, J. (1994). Mind and world. Cambridge, MA: Harvard University Press.

McDowell, J. (1995). Knowledge and the internal. Philosophy and Phenomenological Research, 55, 877-893. doi:10.2307/2108338

McDowell, J. (1998a). Précis of mind and world. Philosophy and Phenomenological Research, 58, 365-431. doi:10.2307/2653515

McDowell, J. (1998b). Having the world in view: Sellars, Kant, and Intentionality. The Journal of Philosophy, 95, 431-490. doi:10.2307/2564576

McDowell, J. (2000). Experiencing the world. In M. Willaschek (Ed.), John McDowell: Reason and nature (pp. 3-18). Münster: Münsteraner Vorlesungen zur Philosophie.

McDowell, J. (2002a). Reponses. In N. H. Smith (Ed.), Reading McDowell on mind and world (pp. 269-303). New York: Routledge.

McDowell, J. (2002b). Knowledge and the internal revisited. Philosophy and Phenomenological Research, 64, 97-105. 


\section{C.-I. LIN}

doi:10.1111/j.1933-1592.2002.tb00144.x

McDowell, J. (2006). Conceptual capacities in perception. In G. Abel (Ed.), Kreativität (pp. 1065-1079). Hamburg: Felix Meiner Verlag.

Halbig, C., Hansberger, A., \& Quante, M. (2000). Secondary qualities or second nature: Which reality for values? In M. Willaschek (Ed.),
John McDowell: Reason and nature (pp. 85-88). Münster: Münsteraner Vorlesungen zur Philosophie.

Sellars, W. (1956). Empiricism and the philosophy of mind. In H. Feigl, \& M. Scriven (Eds.), Minnesota studies in the philosophy of science (pp. 253-329). Minneapolis: University of Minnesota Press. 